\title{
Discontinuation of Long-Acting Reversible Contraceptive methods and associated factors among women in health facilities of Bahir Dar city, Northwest Ethiopia: A Cross-sectional study
}

Yilkal Dagnaw Melesse ( $\sim$ dagnaw.yilkal@gmail.com )

Assosa University

Ambaye Minayehu Zegeye

Assosa University

Getahun Deguale Kebede

Assosa University

Yaregal Dessalew Tarik

Assosa University

Selamawit Lake Fenta

Bahir Dar University

Alemwork Abie Getu

Bahir Dar University

Toyiba Hiyaru Wassie

Bahir Dar University

Tewodros Worku Bogale

Injibara University

Magarsa Lami Dabalo

Haramaya University

Paulos Jaleta

Assosa University

Research Article

Keywords: Discontinuation, Reversible long-acting contraceptives, Bahir Dar, Ethiopia

Posted Date: January 21st, 2022

DOI: https://doi.org/10.21203/rs.3.rs-1212900/v1

License: (c) (1) This work is licensed under a Creative Commons Attribution 4.0 International License.

Read Full License 
Page $2 / 26$ 


\section{Abstract}

Background: Long-acting reversible contraceptive discontinuation is the removal or switch to other methods before completion of duration due to any issue. Discontinuation of these methods exposes a woman to unwanted pregnancy, unsafe abortions, and unplanned births that affect millions of women worldwide. Despite the improvement in the availability and utilization of these methods, discontinuation is becoming high. There is no study conducted on discontinuation and associated factors of long-acting reversible contraceptives in Bahir Dar city, Northwest Ethiopia.

Objective: This study aimed to assess the proportion and associated factors of discontinuation of LongActing Reversible Contraceptives among women in health facilities of Bahir Dar city, Northwest Ethiopia from April 1 to May 30/ 2021.

Methods: health facility-based cross-sectional study was conducted on 415 participants from April 1 to May 30/ 2021. Data were collected through a face-to-face interview-guided questionnaire by using a systematic random sampling technique. Epi Data version 3.1 and Statistical Package for Social Sciences version 25 were used for data entry and analysis respectively. Bivariable and multivariable logistic regression analysis were employed; a P-value of less than 0.05 was considered a statistically significant factor for discontinuation

Results: The overall proportion of discontinuation of long-acting reversible contraceptives was $66.3 \%$ (95\% Cl: 61.42-69.13). No formal education (AOR=.49; 95\% Cl:0.30-0.82), primary school education $(A O R=.39 ; 95 \% \mathrm{Cl}: 0.18-0.81)$, desire to be pregnant in the near future (AOR=2.57; 95\% Cl:1.64-4.02), no past history of modern contraceptive utilization ( $A O R=2.01 ; 95 \% \mathrm{Cl}: 1.19-3.38)$, lack of counseling about benefits (AOR=1.68; 95\% Cl:1.08-2.62) and side effects (AOR=1.95; $95 \mathrm{Cl}: 1.21-3.16)$ were the associated factors for discontinuation.

Conclusion: The overall discontinuation of long-acting reversible contraceptives among women was low compared to Ethiopian Demographic Health Survey 2016. Education, the desire of pregnancy shortly, no history of contraceptive utilization, lack of counseling about the benefits, and side effects were factors for discontinuation. Therefore, health professionals better give counseling, implement early management of side effects and reassure clients of any concerns.

\section{Background}

Discontinuation of Long-acting reversible contraceptives is starting use and cessation or switching to other methods for any reason before completion of duration (1). Intrauterine contraceptive devices (IUCD) and implants are known as long-acting reversible contraceptives (LARCs). They represent highly effective methods of modern birth control and their duration of action is long ranging from 3 to 10 years (2). One of the fundamental practices of women's health care is the provision of effective contraception like LARCs; the annual pregnancy rates for IUCDs are less than 1 per 100 women and the clinical failure rate of Implant is less than $1 \%(3)$. 
Decreasing discontinuation of LARCs is an excellent strategy to avoid or at least reduce unwanted pregnancy (UP), which affects millions of women in the world (4). Discontinuation of LARCs contributes to unplanned pregnancies which expose a risk to the health of women, affects the family size, and contributes to higher fertility rate, social, economic, and physical health problems(5). Although there is an improvement in long-acting reversible contraception usage, discontinuation is becoming a major problem. In low-income countries, $20 \%$ of women discontinue LARCs within one year of insertion (6).

There was a good achievement in reduction of fertility rate and increasing modern contraceptive prevalence rate observed in the Millennium Development Goals era. Despite this, the government of Ethiopia is again running to address Sustainable Development Goal 3(SDG-3) which proposed that roughly $20 \%$ of married reproductive age women will use LARCs by 2030 (7).

Discontinuation of LARCs was high in Ethiopia in which $45 \%$ of IUCD and $61 \%$ of implants were discontinued by three years of utilization. The high LARCs discontinuation is coupled with low uptake; is a big challenge to achieve the targeted prevalence rate in the country and Among the associated factors of discontinuation, didn't receive pre-insertion counseling, experienced side effects, and desire for pregnancy were mentioned (8). Long-acting reversible contraceptives can prevent thousands of cases of maternal mortality by preventing annually occurring 87 million unintended pregnancies (9). Discontinuation of LARCs is higher in third world countries than in the developed world; in Myanmar, LARCs discontinuation is $7 \%$ for intrauterine contraceptive devices, $0.2 \%$ for implants, and $28 \%$ for women shifted to other modern contraceptives (10).

Discontinuation of LARCs is high in developing countries and most of these occur among women who are at risk of unplanned pregnancy (11). World health organizations and national governments had started promoting LARCs as a strategy to implement family planning programs (12). Despite increases in availability, effectiveness, and knowledge on LARCs in Ethiopia, the overall utilization of LARCs is very low and there is high discontinuation including the Amhara region (13).

There is no study conducted on the proportion and associated factors of all the three components of LARCs (IUCD, Jaddles, and Implanon) in Bahir Dar city. Therefore, this study was forwarded to have the contribution in searching of the associated factors and help to decrease the bad outcomes of discontinuation of LARCs in Bahir Dar city health facilities.

Findings from this study will direct health professionals to improve counseling service provision, the ability of planning and decision-making to look at possible solutions regarding LARCs. The findings will also be an input for the Amhara regional health bureau, health planners, and other concerning organizations working in the area of family planning and maternal health. Moreover, this study will also be used as baseline data for researchers who want to study in this area of research. Finally, the investigator believes that the findings from this study will help to the achievement of sustainable development goal 3 of family planning at the country level.

\section{Conceptual framework}


The detailed factors or variables for discontinuation of LARCs are mentioned in the section of the Conceptual framework (Figure 1)

\section{Methods And Materials}

\section{Study setting and Design}

An institution-based cross-sectional study design was conducted in Bahir Dar city health facilities which provide Family Planning services including LARCs from April 1 to May $30 / 2021$. Bahir Dar is the capital city of Amhara National Regional State in the Federal Democratic Republic of Ethiopia located in the Northwest direction at $565 \mathrm{~km}$ away from Addis Ababa, the capital city of Ethiopia (14). The population of Bahir Dar City was estimated to be 389,177 in the year 2020 based on the 2007 census (15).

The Bahir Dar city has one specialized referral, one comprehensive referral, and one primary public hospital (Tibebe Ghion, Felege Hiwot, and Addis Alem respectively), 6 health centers (Abay health center, Han health center, Shimbet health center, Menelik health center, Bahir Dar health center, and Shum-abo health center), 10 health posts, two specialized clinics (family guidance association and Maire stope), 4 private general hospitals and 35 medium private clinics (16). Family guidance association and Maire stop specialized clinics are non-governmental facilities that provide consistent family planning services including implants and Intrauterine contraceptive devices. Therefore, these were included in this study.

\section{Source population}

All reproductive-age women who were using long-acting reversible contraceptive methods in health facilities of Bahir Dar city.

\section{Study population}

All reproductive-age women who were using long-acting reversible contraceptive methods came to selected health facilities of Bahir Dar city with contraceptive-related issues during the study period. Inclusion criteria and Exclusion criteria

\section{Inclusion criteria}

All reproductive age women who were using LARCs came to the selected health facilities for any issue concerning the method before completion of duration; like removal, side effects, and follow-up during the actual data collection period.

\section{Exclusion criteria}

All women who were using LARCs came to the selected health facilities for the removal of LARCs who got the service outside Bahir Dar city and who came to change Implanon to Jaddles, Jaddles to Implanon, and implants to IUCD or vice versa.

\section{Sample size determination}


Accordingly, for the first and second specific objectives, the sample size was calculated separately, and the larger sample size was taken to be used for this study. Sample size determination for objective one was calculated by using single population formula by considering the following assumptions: $95 \% \mathrm{Cl}$, the prevalence $(P)$ of LARC discontinuation taken from a study conducted in Hawassa city which was $57 \%$ with a non-response rate of $10 \%(1)$.

$\mathrm{N}=Z\left(\frac{\alpha}{2}\right)^{2} \frac{p(1-P)}{d^{2}}$, Where $\mathrm{n}$ is the minimum sample size required, $\mathrm{p}$ is expected proportion of discontinued LARCS, $z=1.96(95 \% \mathrm{Cl})$ and $d=0.05$ is the margin of error between the sample and the population. Applying the equation; $\mathrm{n}=(1.96)^{2} \frac{0.57 * 0.43}{(0.05)^{2}}=377$, with $10 \%$ non-response rate the final sample was calculated as $377+(377 * 10 / 100)=377+37.8=377+38=415$.

Sample size determination for objective two was calculated by using double population formula with Epiinfo version 7.2.1 Stat Calc by considering the following assumptions: Two-sided significant level (1 alpha): $95 \% \mathrm{Cl}$, power ( 1 - beta, \% chance of detecting):80\%, the ratio of Exposed: Unexposed $=1$, and nonresponse rate of $10 \%$. Exposed in this case means exposed to factors for removal (experiencing side effects, lack of counseling, and desire for pregnancy). These factors were taken from a study conducted in Hawassa city (1) (Table 1).

Table1 1: Sample size determination using associated factors of discontinuation of reversible long-acting contraceptive methods among women in Bahir Dar city Health facilities, Northwest Ethiopia, 2021.

\begin{tabular}{|llll|}
\hline S.no & $\mathbf{1}$ & $\mathbf{2}$ & $\mathbf{3}$ \\
\hline Factors & $\begin{array}{l}\text { Removal due to } \\
\text { experience of side }\end{array}$ & $\begin{array}{l}\text { Removal due to lack } \\
\text { of counseling }\end{array}$ & $\begin{array}{l}\text { Removal due to desire } \\
\text { for pregnancy }\end{array}$ \\
\hline Reference & 1 & 1 & 1 \\
\hline AOR & 2.09 & 2.48 & 2.34 \\
\hline Power & 80 & 80 & 80 \\
\hline Cl & $95 \%$ & $95 \%$ & $95 \%$ \\
\hline Ratio & 1 & 1 & 1 \\
\hline $\begin{array}{l}\text { \% of un exposed } \\
\text { outcome }\end{array}$ & 47.2 & 25.8 & 44.8 \\
$\begin{array}{l}\text { \% of the exposed } \\
\text { outcome }\end{array}$ & 35.3 & 44.8 & 36.4 \\
\hline $\begin{array}{l}\text { Sample size with 10\% } \\
\text { non-response rate }\end{array}$ & 286 & 207 & 240 \\
\hline
\end{tabular}

Finally, the calculated sample size for the second objective with a $10 \%$ nonresponse rate is less than that of the first objective. Therefore, the sample size of the first objective was the sample size of this study 
which is 415 .

\section{Sampling technique}

All public health facilities of Bahir Dar city which has LARC services were included in the study (3 hospitals and 6 health centers). Two Nongovernmental specialty clinics (Family Guidance Association and Maire stops) were also included since they provide LARCs service. The other private health facilities were not included since they have no full LARC services (insertion and removal). Hence a total of eleven (11) health facilities were included in this study.

The study subjects were identified based on the information obtained from the Family planning registration book. The information obtained from two Months report from the family planning registration book of one year preceding this study period in similar months observed that a total of 830 women were booked or used LARCs in health facilities of Bahir Dar City. The average two-month client flows for health facilities were taken.

The proportionally allocated sample size for each facility was calculated as $\mathrm{ni}=\mathrm{Ni}{ }^{*} \mathrm{nf} / \mathrm{N}$; where $\mathrm{ni}=$ sample size in each facility,

$\mathrm{Ni}=$ number of women who were using LARCS in each facility within two months,

$\mathrm{nf}=$ total sample size of this study (415), and

$\mathrm{N}=$ all women in Bahir Dar City health facilities who were using LARCs (830).

Finally, the total sample size was met by using the systematic sampling technique of daily caseload. $\mathrm{K}$ was calculated by dividing the total two-month caseload in Bahir Dar City for the total proportional allocated cases as $830 / 415=2$. Therefore, every other woman was included in the sample until the total sample size for this study was obtained. Based on the client's card order information was collected from participants after completion of the service. The procedure was continued throughout the data collection period until the required sample size was achieved (Figure 2).

\section{Variables}

\section{Dependent variable}

Long-acting reversible contraceptives discontinuation (Yes/No)

\section{Independent variables}

Socio-demographic characteristics

Age, marital status, religion, ethnicity, occupation, maternal educational status, husband's educational status, and husband's occupation

Obstetric related factors 
Parity, number of living children, history of abortion, and desire for pregnancy in near future.

Contraceptive method and Health facility-related factors

Past contraceptive utilization, type of LARC used, side effects, follow-up, type of health facility, counseling, who choose LARC, has no husband/go abroad, loss of implant in the arm, the expulsion of IUCD/missing of string, and becoming pregnant/method failure

\section{Other factors including Myths and Misconceptions}

Peer pressure/neighbor's influence, husband objection/order, decreasing of sexual activity/Libido, fear of migration of the LARC to other body parts, fear of infertility, and fear of cancer.

\section{Operational Definition}

Long-acting reversible contraceptive methods (LARCs): contraceptive methods which serve as 3-10 years but can be removed at any time (not permanent); only implants and IUCD (17).

Discontinuation of LARCs: starting using and cessation of long-acting reversible contraceptives before completion of duration due to any issue concerning with the method (1).

Misconception: without scientific evidence, the woman perceived LARCS can cause infertility, cancer, shifting to other body sites, and reduce sexual activity (18).

Follow-up: is schedule or appointment given for the mother to come to health facilities on regular basis or when she has concerns with the method not only appointed by the due date.

Side effect: when the women develop at least one of the following after LARC insertion: menstrual disruption, insertion site pain, difficultly to work, headache, acne, and weight change $(14,17)$.

\section{Data Collection Instruments, Collectors, and Procedures}

The data for this study were collected by using a pre-tested structured interview-based questionnaire which was adapted from previous literature (1) with some modifications. There are four main parts to this questionnaire. These are socio-demographic characteristics, obstetric-related factors, contraceptive method and health facility-related factors, and others factors including myths and misperceptions about LARCS. To check for its consistency, the questionnaire was first developed in English and translated into Amharic and then finally back to English.

Data collectors were five Nurses ( 3 diplomas and 2 degrees) and six Midwives ( 2 diplomas and 4 degrees) who were not working in health facilities. Data were collected from study subjects through a face-to-face interview-guided questionnaire. Data were collected and the questionnaire was filled by data collectors after obtaining written consent from the study participants.

Data collectors have gathered information from study subjects around the family planning room after completion of the service provided by health care providers. Three supervisors with a qualification of 
degree and skilled in data collection supervised the data collection. The principal investigators supervised and provided all necessary items for data collection, checked completeness and logical consistency, and solve problems during the time of data collection daily.

\section{Data Quality Assurance}

To assure the quality of data, properly designed data collection tools were used. Data collectors and supervisors were trained about research objectives, data collection tools, procedures, and interview techniques for one day. Before the actual data collection, the questionnaire was tested on $5 \%$ of the total sample size ( 21 women) who were used LARC methods at Zenzelima Health Center ( 11 women) and Meshenti Health Center (10 women) to check the contextually of data.

The questionnaires were revised and get amended as necessary after the pretest was done. The principal investigator, together with three supervisors supervised the technique of data collection and completeness of tools on the daily basis, and accordingly, appropriate feedback was forwarded. To resolve differences and assure their quality, data double entry was performed.

\section{Data Processing, Analysis, and presentation}

After data collection, the questionnaire was checked for completeness, data entered, coded, checked, and cleared by using EPI DATA V-3.1 and then exported to Statistical Package for Social Science [SPSS] V-25 computer software. Then analysis (Descriptive statistic to summarize data) and Bi-variate logistic regression were performed at $95 \%$ confidence level with LARCs discontinuation for each factor. From the bivariate regression analysis, variables at $p<0.25$ were entered into multivariate logistic regression analysis with a $95 \%$ confidence level, multicollinearity test was done to check the correlation between each independent variable, and the model goodness of fit was tested using Hosmer and Lemeshow test.

Variables with a p-value less than 0.05 in the multivariate logistic regression analysis were considered as statistically significant factors for LARCs discontinuation. Finally, the descriptive statics results were presented using text, tables, and graphs based on the type of data.

\section{Ethical Consideration}

The study gets research ethics approval from Bahir Dar University, College of Medicine and Health Sciences Institutional Review Board (IRB). The permission and agreement consent was obtained from the Bahir Dar city Health Department and the selected health facilities before data collection.

Voluntary, informed, written, and signed consent were obtained from heads of selected health facilities in Bahir Dar city and participants before data collection started. The participants were also assured that their responses could not result in any harm and offered full rights not to participate, the name did not write on the tool, and confidentiality was maintained.

\section{Results}




\section{Sociodemographic Characteristics of study participants}

A total of 415 women had responded to the questionnaires making a response rate of $100 \%$. The age of the study participants was between 18 and 43 years. Out of the total respondents, $111(26.7 \%)$ were found to be in the age category of $>35$ years followed by the age group of $25-29$ accounts for $106(25.5 \%)$. Twohundred ninety-four (70.8\%) were married followed by single, 59(14.3\%) and 304(73.3\%) were orthodox Christians. In Ethnicity, 387(93.3\%) were Amhara. Looking at educational status, 109(26.3\%) had secondary school. From the partner's educational status, 106(36\%) attained college and above followed by secondary school, 73(24.8\%)(Table 2). 
Table 2

Sociodemographic characteristics of long-acting reversible contraceptive users in health facilities of Bahir Dar city, Northwest Ethiopia, 2021 $(n=415)$

\begin{tabular}{|c|c|c|c|}
\hline \multicolumn{4}{|c|}{ Variables Categories Frequency Percentage } \\
\hline \multirow[t]{5}{*}{ Age } & $<20$ & 12 & 2.9 \\
\hline & $20-24$ & 84 & 20.3 \\
\hline & $25-29$ & 106 & 25.5 \\
\hline & $30-34$ & 102 & 24.6 \\
\hline & $\geq 35$ & 111 & 26.7 \\
\hline \multirow[t]{4}{*}{ Marital status } & Married & 294 & 70.8 \\
\hline & Single & 59 & 14.3 \\
\hline & Divorced & 32 & 7.7 \\
\hline & Widowed & 30 & 7.2 \\
\hline \multirow[t]{4}{*}{ Religion } & Orthodox & 304 & 73.3 \\
\hline & Muslim & 82 & 19.8 \\
\hline & Protestant & 17 & 4.1 \\
\hline & Others@ & 12 & 2.8 \\
\hline \multirow[t]{3}{*}{ Ethnicity } & Amhara & 387 & 93.3 \\
\hline & Agew & 18 & 4.3 \\
\hline & Oromo & 10 & 2.4 \\
\hline \multirow[t]{5}{*}{ Educational level } & Unable to read \& write & 66 & 15.9 \\
\hline & Read \& write & 76 & 18.3 \\
\hline & Primary & 59 & 14.2 \\
\hline & Secondary & 109 & 26.3 \\
\hline & College \& above & 105 & 25.3 \\
\hline
\end{tabular}

(๑)=catholic \& Adventist, (๑)=labor, self-employer 


\begin{tabular}{|c|c|c|c|}
\hline \multicolumn{4}{|c|}{ Variables Categories Frequency Percentage } \\
\hline \multirow[t]{5}{*}{ Maternal occupation } & Housewife & 172 & 41.4 \\
\hline & Merchant & 61 & 14.7 \\
\hline & Private employee & 45 & 10.8 \\
\hline & Student & 59 & 14.3 \\
\hline & Government employee & 78 & 18.8 \\
\hline \multirow[t]{5}{*}{ Husband's education } & Unable to read \& write & 30 & 10.2 \\
\hline & Read \& write & 41 & 14.0 \\
\hline & Primary & 44 & 15.0 \\
\hline & Secondary & 73 & 24.8 \\
\hline & College\& above & 106 & 36.0 \\
\hline \multirow[t]{6}{*}{ Husband's occupation } & Government employee & 66 & 22.4 \\
\hline & Private employee & 54 & 18.4 \\
\hline & Merchant & 104 & 35.4 \\
\hline & Farmer & 39 & 13.3 \\
\hline & Student & 18 & 6.1 \\
\hline & Others@๑ & 13 & 4.4 \\
\hline \multicolumn{4}{|c|}{ ๑)=catholic \& Adventist, ๑๑)=labor, self-employer } \\
\hline
\end{tabular}

\section{Obstetrics Related Characteristics}

One hundred ninety-nine (48\%) of the respondents were multipara. Out of those who gave birth, 228(55\%) women have one to two live children. Among the participants, 207(49.9\%) women had a history of abortion, and 254(61.2\%) women had a desire for pregnancy soon(Table 3). 
Table 3

Obstetrics-related characteristics of LARC user women in health

facilities of Bahir Dar city, Northwest Ethiopia, 2021 $(n=415)$.

\begin{tabular}{|llll|}
\hline Variables Categories Frequency Percentage & & \\
\hline & Nullipara & 64 & 15.4 \\
& Primipara & 70 & 16.9 \\
& Multipara & 199 & 48.0 \\
& Grand Multipara & 82 & 19.7 \\
\hline Number of living children & No children & 78 & 18.8 \\
& 1-2 children & 228 & 55.0 \\
& $3-4$ children & 52 & 12.5 \\
& $\geq 5$ children & 57 & 13.7 \\
\hline History of abortion & Yes & 207 & 49.9 \\
& No & 208 & 50.1 \\
\hline Desire for pregnancy & Yes & 254 & 61.2 \\
& No & 161 & 38.8 \\
\hline Time to conceive(n=254) & Within two years & 162 & 63.8 \\
& After two years & 92 & 36.2 \\
\hline
\end{tabular}

\section{Contraception and Health facility Related Characteristics}

Of the total participants, 298(71.8\%), 95(22.9\%), and 22(5.3\%) were Implanon, Jaddles, and IUCD users respectively. Among these, $327(78.8 \%)$ used modern contraceptives before the current LARCs. Out of the 165(50.5\%) had used injectable. Concerning counseling services, 200(48.2\%) did not get counseling about the benefits of the LARCs whereas $260(62.7 \%)$ of participants did not get counseling about possible side effects.

Regarding the follow-up, half of the participants, 208(50.1\%) were appointed and 303(73\%) of the total participants had experienced side effects. Among suggested reasons identified for removal, side effects of LARCs were the first accounted for $102(37.1 \%)$ mainly due to menstrual irregularity accounts $52(51 \%)$ (Table 4) 
Table 4

Contraception and health facility-related characteristics of LARC users in Health facilities of Bahir Dar city, Northwest Ethiopia, 2021 ( $n=415)$.

\begin{tabular}{|c|c|c|c|}
\hline \multicolumn{4}{|c|}{ Variables Categories Frequency Percentage } \\
\hline \multirow[t]{3}{*}{ Type of LARC used } & Implanon & 298 & 71.8 \\
\hline & Jaddles & 95 & 22.9 \\
\hline & IUCD & 22 & 5.3 \\
\hline \multirow[t]{2}{*}{ Past contraceptive utilization } & Yes & 327 & 78.8 \\
\hline & No & 88 & 21.2 \\
\hline \multirow[t]{4}{*}{ Method of contraceptive used $(n=327)$} & OCP & 104 & 31.8 \\
\hline & Injectable & 165 & 50.5 \\
\hline & IUCD & 4 & 1.2 \\
\hline & Implants & 54 & 16.5 \\
\hline \multirow[t]{4}{*}{ Place of LARC given } & Hospital & 114 & 27.5 \\
\hline & Health center & 208 & 50.1 \\
\hline & Family guidance & 53 & 12.8 \\
\hline & Maire stops & 40 & 9.6 \\
\hline \multirow[t]{2}{*}{ Counseling on the benefit of LARC } & Yes & 215 & 51.8 \\
\hline & No & 200 & 48.2 \\
\hline \multirow[t]{2}{*}{ Counseling on side effects of LARC } & Yes & 155 & 33.3 \\
\hline & No & 260 & 62.7 \\
\hline \multirow[t]{2}{*}{ Ever faced side effects } & Yes & 303 & 73.0 \\
\hline & No & 112 & 27.0 \\
\hline \multirow[t]{5}{*}{ LARC choose by } & Own choice & 181 & 43.6 \\
\hline & My husband & 76 & 18.3 \\
\hline & Health professionals & 104 & 25.1 \\
\hline & HEW & 20 & 4.8 \\
\hline & Neighbors/friends & 34 & 8.2 \\
\hline
\end{tabular}




\begin{tabular}{|llll|}
\hline Variables Categories Frequency Percentage & & & \\
\hline The main reason to choose LARC & Safety & 117 & 28.2 \\
& Effectiveness & 57 & 13.7 \\
& Long protection & 141 & 34.0 \\
& Reduce appointment & 52 & 12.5 \\
& Removed at any time & 33 & 8.0 \\
& Immediate fertility return & 15 & 3.6 \\
\hline Follow up/appointment & Yes & 208 & 50.1 \\
& No & 207 & 49.9 \\
\hline Reasons for discontinuation of LARCs(N=275) & Side effects & 92 & 33.5 \\
& To be pregnant & 90 & 32.7 \\
& No husband/divorce & 40 & 14.5 \\
& Loss of implant in the arm & 10 & 3.6 \\
& Missed IUCD string & 6 & 2.2 \\
& Become pregnant & 3 & 1.1 \\
& Myths/Misconception & 34 & 12.4 \\
\hline Removal due to side effect (N=92) & Menstrual irregularity & 48 & 52.2 \\
& Weight change & 17 & 18.5 \\
& Unusual headache & 15 & 16.3 \\
& Insertion site pain & 4 & 4.3 \\
& Difficulty to work & 8 & 8.7 \\
\hline
\end{tabular}

\section{Other factors including myths/misconceptions}

Among participants, a total of 69 women requested the removal of LARCs due to myths/misconceptions, but only $34(12.4 \%)$ of them discontinued LARCs after counseling. Husband objection/order was the main reason which accounts for $20(28.9 \%$ (Table 5). 
Table 5

Myth/misconception characteristics of LARC user women in health facilities of Bahir Dar City, Northwest Ethiopia, 2021 $(n=69)$

\begin{tabular}{|lll|}
\hline Variables Frequency Percentage & & \\
\hline Peer pressure/neighbors' influence & 13 & 18.8 \\
\hline Decreasing sexual activity/libido & 16 & 23.2 \\
\hline Husband objection/order & 20 & 28.9 \\
\hline Fear of migration to other body parts & 8 & 11.6 \\
\hline Fear of infertility & 7 & 10.2 \\
\hline Fear of cancer & 5 & 7.3 \\
\hline
\end{tabular}

The proportion of Discontinuation of Long-Acting Reversible Contraceptives

From a total of 415 study participants, $66.3 \%$ (95\% Cl: 61.42-69.14). The discontinuation of Implanon, Jaddles, and IUCD was $34.3 \%, 21 \%$, and $11 \%$ respectively

\section{Duration of Long-Acting Reversible Contraceptive utilization Before Discontinuation}

More than half of the participants discontinued after one and before three years of utilization which accounts for 157(57.1\%), 54(19.6\%) discontinued between 3 and 4 years, and 15(5.45\%) were discontinued after 4 years of utilization. The detailsares shown below (Figure 3).

\section{Factors Associated with Discontinuation of Reversible Long-Acting Contraceptives}

Findings from bivariate logistic regression analysis of this study resulted that maternal religion, maternal occupation, maternal education, desire to be pregnant soon, type of LARC used, past contraceptive utilization, counseling about the benefit of LARCs, side effects, and follow-up were entered into multivariate regression analysis. However, after adjusting other variables in a multivariable logistic regression analysis only maternal education, pregnancy desire in near future, no past contraceptive utilization, not counseled for benefit of LARCs, and experiencing side effects were found significantly associated with LARCs discontinuation.

According to this finding, the odds of discontinuation of LARCs among women who have no formal education were $51 \%$ less likely than college and above (AOR=0.49; $95 \% \mathrm{Cl}: 0.30-0.82$ ). The odds of discontinuation of women who attended a primary level of education were reduced by $61 \%$ than college and above (AOR=0.39; 95\% Cl: 0.18-0.81)

This study also revealed that the odds of discontinuing LARCs among women who desire to be pregnant shortly were 2.6-fold higher than their counterparts (AOR=2.57; 95\% Cl: 1.64-4.02). Women who didn't use contraceptives before current LARC utilization were about 2 times more likely to discontinue than their counterparts (AOR=2.01; 95\% Cl: 1.19-3.38). 
The odds of discontinuing LARCs among women who experienced side effects were 2 times higher than those who didn't experience side effects (AOR=1.95; $95 \mathrm{Cl}: 1.21-3.16)$. This study also showed that the odds of discontinuation of long-acting reversible contraceptives among women who had not received counseling about the benefit of LARCs was 1.7 times higher compared to their counterparts (AOR=1.68 95\% Cl:1.08-2.62) (Table 6).

\section{Discussion}

In this study, the overall proportion of LARCs discontinuation among women was $66.3 \%$ (95\% Cl: $61.42-$ 69.14). The discontinuation of Implants was $55.3 \%$ of which Implanon was $34.3 \%$ and the discontinuation of IUCD was $11 \%$. Discontinuation of LARCS in this study is low compared with the secondary data analyzed from EDHS 2016 , where $61 \%$ of implants and about $45 \%$ of IUCDs users were discontinued at the end of three years (8). This might be due to the discrepancy of population structure of the national pattern and variation in the duration of utilization before discontinuation.

This study is also lower than a study done in Colorado, Western United States that is $81.7 \%$ (19). The possible explanation might be the discontinuation in Colorado was within 30 months of utilization. The other explanation might be most of the health professionals in our setup might didn't easily accept complaints of removal since the proportion of utilization of LARCs is low (18.4\%) (20).

However, discontinuation of LARCs in this study is higher than studies conducted in the Sidama region, southern Ethiopia, 10.3\% (21), and Hawassa City, southern Ethiopia, 56.6\% (1). This difference might be due to the duration of utilization in the Sidama region being within one year and the presence of the religious varieties in the Sidama region and Hawassa city as most of the study participants in Bahir Dar were Orthodox Christian. On the other hand, recently in Ethiopia customers visiting health facilities for removal is also increasing since in earlier times a significant number of users think impossible to discontinue the LARC before the due date after once inserted due to the awareness gap (7). Also due to the pandemic of COVID-19 health care providers might not expense much time for detailed counseling.

The current finding is also higher than the study conducted in Uganda, 6.8\% (22), Nigeria, $58.1 \%$ (23), and Maryland, $33.2 \%$ (24). This difference might be due to culture and religion as more than $90 \%$ of this study participants were orthodox Christian. This difference might also be due to inadequate pre-insertion counseling as evidenced by $62.7 \%$ of the participants in this study didn't receive counseling about side effects and didn't receive counseling on the benefit of LARCs was one of the factors for LARCS discontinuation.

In this study, the odds of discontinuation of LARCs were reduced by $51 \%$ and $61 \%$ among women who have no formal education and attended primary school respectively compared with women who attended college and above. This is in line with related studies conducted in Bahir Dar, northwest Ethiopia (14), and Debre Markose town, northeast Ethiopia (25). The possible explanation might be women who had higher education levels might seek healthcare sooner than their counterparts when they have complaints and any disturbance from normal physiology (14). 
This finding is not supported by a study done in the Sidama region, Southern Ethiopia (21), and Hawassa City, Southern Ethiopia (1). This is incoherent to my expectation and the possible reasons could be the differences in sociocultural of the population.

This study revealed that the odds of discontinuation of LARCs among women who desire to be pregnant soon were 2.6 times higher than their counterparts. This is in agreement with studies done in Ambo town, Central Ethiopia (26), Hawassa city (1), analyzed of EDHS 2016 data (8), Kenya(27), Nigeria (28), and Zambia (29). The possible reason might be the improper choice of the method as the nature of the method is long-acting. Evidence shows that LARCs must be removed when the clients have a desire to conceive (30). The other possible reason might be women with less or who have no children might intend to have children as evidenced by $19 \%$ and $55 \%$ of the study participants in this study had no alive children and have 1-2 children respectively.

The odds of discontinuation of LARCs among women who have not used any modern contraceptive before the current LARC were about 2.0 times high likely than their counterparts. This finding is not supported by studies conducted in the Sidama region (21), Hawassa city (1), and worldwide (4). This could be because experienced mothers acquired the necessary knowledge and attitude towards the LARCs, while others could be influenced by false beliefs, myths, and misconceptions. The other possible reasons could be fear of delays in pregnancy and disagreement on the method used with a partner.

The odds of discontinuation of LARCs among women who had not received pre-insertion counseling services about the benefits of the LARCs was 1.7 times higher than from their counterparts. This finding is not agreed with a study conducted in Myanmar (10). The suggested explanation for this might be due to the low socio-economic status, poor quality of services, unfavorable participants' attitudes towards LARC in our set up than Myanmar. This is evidenced by only $30 \%$ of all women using modern contraceptives being informed at the time they started the current method use about the method's side effects, what to do if they experience side effects, and other possible solutions (30).

The odds of discontinuing LARCs among women who experienced side effects were about 2.0 times higher than those who did not experience side effects. This is consistent with the studies conducted in Hawassa (1), analysis of EDHS 2016 data (8, 31), Nigeria (32), South Africa (33), Bangladesh (34), and North America (24). The most possible reason for this might be once women developed side effects, they may not tolerate the counseling and management services delivered by health professionals for their complaints due to fear of happening different complications on their health in the future (14).

On the other view, it may be due to discomfort; not well addressed pre-insertion counseling about possible side effects or development of side effects may lead to other physiological or psychological effects. Unexpected changes in menstrual bleeding due to the nature of the method by itself might enforce women to seek removal (26). Also, when there is the development of side effects women might be influenced by their relatives and partners (35).

\section{Limitation}

Page $18 / 26$ 
Since this study was conducted on reversible long-acting contraceptive discontinuation as a whole unlike most other studies which were done on a single contraceptive, it was somewhat challenging to obtain literature in line with the title (especially in Ethiopia).

\section{Conclusion And Recommendations}

The overall discontinuation of reversible long-acting contraceptives among women who were using LARCs was found to be low compared to the analysis of EDHS 2016. The associated factors for discontinuation of LARCs among user women of reproductive age were educational level; the desire to pregnant soon did not use modern contraceptives before reversible long-acting contraceptives, not received counseling about the benefit of LARCs, and experienced side effects. Therefore, health professionals better give counseling, implement early management of side effects and reassure clients of any concerns.

\section{Abbreviations}

AOR: Adjusted Odd Ratio; COR: Crude Odd Ratio; EDHS: Ethiopian Demographic Health Survey; FP: Family Planning; HC: Health Center; IUCDs: Intra-Uterine Contraceptive Devices; LARCs: Long-Acting Reversible Contraceptives; SDG: Sustainable Development Goals; SDI: Sub-dermal Implants; UP: Unplanned Pregnancy

\section{Declarations}

\section{Ethical Approval and Consent to Participate}

This study was conducted in accordance with the Declaration of Helsinki that provides guidance for the researcher to protect research subjects. The study was approved by Institutional Review Board of Bahir Dar University, College of Medicine and Health Sciences, (IRB 0812/2021) on March 29, 2021. An official letter of co-operation was written to Bahir Dar city Health Department. A formal letter was also obtained from the administrative director of each health facility (Tibebe Ghion Specialized Hospital, Felege Hiwot Comprehensive Specialized Hospital, Addis Alem Primary Hospital, Bahir Dar Health Center, Han Health Center, Abay Health Center, Menelik Health Center, Sum Abo Health Center, Shimbet Health Center, Family Guidance Association, and Maire Stop special clinic).

Before data collection respondents were informed about the objective and purpose of the study to get written informed consent from each respondent. At the time of data collection written informed consent was obtained from each study participant for those ages greater than 18 years and from parents/guardians for those ages less than 18 years. All respondents were assured that the data would not have any negative consequences on many aspects of their life. The participants were also assured that their responses could not result in any harm and offered a full right to participate or decline from participating in the study and the study participants assured for an attainment of confidentiality of the 
information obtained from them. Their name did not written on the tool. Their privacy was guaranteed during the whole period of the study by anonymous completion of the questionnaires. For the respondents, it was notified that they have the right to refuse or terminate at any point of data collection.

\section{Competing interests}

The authors declare that they have no competing interests.

\section{Consent to Publish}

Not applicable

\section{Availability of Data and Materials}

The data supporting the findings of this study are available at the hand of co-responding author but some restrictions may apply to the availability of these data as there are some sensitive issues. However, data are available from the corresponding author (Yilkal Dagnaw) upon reasonable request.

\section{Funding}

Assosa University as a requirement for postgraduate studies supports this research financially. The university has no role in the design of the study, collection, analysis, and interpretation of the data, and in writing the manuscript.

\section{Author contributions}

YM developed the protocol and was involved in the design, selection of study, and developing the initial drafts of the manuscript. SF, AG, and TW are involved in quality assessment. YM, AZ, GK, YT, PW, TB, and MD prepared and revised subsequent drafts as well as prepared the final draft of the manuscript. All authors read and approved the final draft of the manuscript.

\section{Acknowledgments}

Our deepest gratitude goes to the department of midwifery, Health sciences college, Bahir Dar University for proper review and approval of this paper. We would like to thank data collectors and study participants for their cooperation and assistance.

\section{Author's information}

1,2lecturers, Department of Midwifery, College Health Sciences, Assosa University, Assosa, Ethiopia

${ }^{3}$ Lecturers, Department of Midwifery, College of Medicine and Health Sciences, Bahir Dar University, Bahir Dar, Ethiopia

${ }^{4}$ Lecturer, Department of Nursing, College of Health Sciences, Assosa University, Assosa, Ethiopia 
${ }^{5}$ Lecturer, Department of Midwifery, College of Health Sciences, Injibara University, Injibara, Ethiopia

${ }^{6}$ Lecturer, School of Nursing and Midwifery, College of Health and Medical Sciences, Haramaya University, Haramaya, Ethiopia

\section{References}

1. Abebe BA, Assefa N, Mengistie B. Discontinuation of Reversible Long-Acting Contraceptive and Associated Factors among Female Users in Health Facilities of Hawassa City, Southern Ethiopia: Cross-Sectional Study. Open Access Journal of Contraception. 2020;11:113.

2. Espey E, Ogburn T. Long-acting reversible contraceptives: intrauterine devices and the contraceptive implant. Obstetrics \& Gynecology. 2011;117(3):705-19.

3. Rademacher $\mathrm{KH}$, Vahdat HL, Dorflinger L, Owen DH, Steiner MJ. Global introduction of a low-cost contraceptive implant. Critical Issues in Reproductive Health: Springer; 2014. p. 285-306.

4. Bahamondes L, Fernandes A, Monteiro I, Bahamondes MV. Long-acting reversible contraceptive (LARCs) methods. Best Practice \& Research Clinical Obstetrics \& Gynaecology. 2019.

5. Teunissen AM, Grimm B, Roumen FJ. Continuation rates of the subdermal contraceptive Implanon ${ }^{\circledR}$ and associated influencing factors. The European Journal of Contraception \& Reproductive Health Care. 2014;19(1):15-21.

6. Adal TG. Early discontinuation of long-acting reversible contraceptives among married and in union women: a systematic review and meta-analysis. Annals of Medical and Health Sciences Research. 2017.

7. Osotimehin B. Family planning as a critical component of sustainable global development. Global health action. 2015;8.

8. Fekadu GA, Omigbodun AO, Roberts OA, Yalew AW. Factors associated with early long-acting reversible contraceptives discontinuation in Ethiopia: evidence from the 2016 Ethiopian demographic and health survey. Archives of Public Health. 2020;78(1):1-10.

9. Sonfield A, Kost K, Gold RB, Finer LB. The public costs of births resulting from unintended pregnancies: National and state-level estimates. Perspectives on sexual and reproductive health. 2011;43(2):94-102.

10. Tin KN, Maung TM, Win T. Factors that affect the discontinuation of family planning methods in Myanmar: analysis of the 2015-16 Myanmar Demographic and Health Survey. Contraception and Reproductive Medicine. 2020;5(1):1-11.

11. Bradley SE, Schwandt $H$, Khan S. Levels, trends, and reasons for contraceptive discontinuation. DHS analytical studies. 2009;20.

12. Samuel M, Fetters T, Desta D. Strengthening postabortion family planning services in Ethiopia: expanding contraceptive choice and improving access to long-acting reversible contraception. Global Health: Science and Practice. 2016;4(Supplement 2): S60-S72. 
13. Biza N, Abdu M. Long-acting reversible contraceptive use and associated factors among contraceptive users in Amhara region, Ethiopia, 2016. A community-based cross-sectional study. Medico Research Chronicles. 2017;4(05):469-80.

14. Sznajder KK, Tomaszewski KS, Burke AE, Trent M. Incidence of discontinuation of long-acting reversible contraception among adolescent and young adult women served by an urban primary care clinic. Journal of pediatric and adolescent gynecology. 2017;30(1):53-7.

15. Cohen R, Sheeder J, Teal SB. Predictors of discontinuation of long-acting reversible contraception before 30 months of use by adolescents and young women. Journal of Adolescent Health. 2019;65(2):295-302.

16. Ohazurike E, Olamijulo JA, Ibisomi L, Olorunfemi G, Oluwole AA. Predictors of Discontinuation of Subdermal Levonorgestrel Implants (Jadelle) at the Lagos University Teaching Hospital, Lagos, Nigeria: An Analytic Cohort Study. African Journal of Reproductive Health. 2020;24(2):48-63.

17. Sseninde J. Factors Associated With Contraceptive Discontinuation Among Women (15-49 Years) In Uganda: Makerere University; 2019.

18. Geja E, Belayneh F, Deresse Legesse DT, Abuka T, Gebremariam A, Gebreyohaness H, et al. Prevalence of Early Removal of Long-Acting Contraceptive Methods and Its Associated Factors in Sidama Regional State, Ethiopia. Open Access Journal of Contraception. 2021;12:35.

19. Melkamu Asaye M, Syoum Nigussie T, Mequannt Ambaw W. Early Implanon discontinuation and associated factors among Implanon user women in Debre Tabor town, public health facilities, Northwest Ethiopia, 2016. International Journal of reproductive medicine. 2018;2018.

20. Nageso A, Gebretsadik A. Discontinuation rate of Implanon and its associated factors among women who ever used Implanon in Dale District, Southern Ethiopia. BMC women's health. 2018;18(1):1-9.

21. Mamo K, Siyoum M. Among Implanon User Women in Ambo town, Central Ethiopia. population. 2019;58.

22. Yehuala T, Melese E, Bogale KA, Dagnew B. Determinants of Implanon Discontinuation among Women Who Use Implanon at Bahir Dar Town Health Institutions, Northwest Ethiopia, 2019: A CaseControl Study. Evidence-Based Complementary and Alternative Medicine. 2020;2020.

23. Haddad L, Wall KM, Vwalika B, Khu NH, Brill I, Kilembe W, et al. Contraceptive discontinuation and switching among couples receiving integrated HIV and family planning services in Lusaka, Zambia. AIDS (London, England). 2013;27(0 1):S93.

24. Isa B, Ibrahim SM, Mandara M, Bako B. Uptake and reason for discontinuation of long-acting reversible contraception in a tertiary hospital: A 5 years retrospective review. African Journal of Medical and Health Sciences. 2020;19(9):142-9.

25. Kungu W, Khasakhala A, Agwanda A. Trends and factors associated with long-acting reversible contraception in Kenya. F1000Research. 2020;9(382):382.

26. Siyoum M, Mulaw Z, Abuhay M, Kebebe H. Implanon discontinuation rate and associated factors among women who ever used Implanon in the last three years in Debre Markos town, Northwest 
Ethiopia, 2016, cross-sectional study. ARC J Public Health Community Med. 2017;2:8-16.

27. Jain A, Reichenbach L, Ehsan I, Rob U. "Side effects affected my daily activities a lot": a qualitative exploration of the impact of contraceptive side effects in Bangladesh. Open access journal of contraception. 2017;8:45.

28. Mrwebi KP, Ter Goon D, Owolabi EO, Adeniyi OV, Seekoe E, Ajayi Al. Reasons for discontinuation of Implanon among users in Buffalo City Metropolitan Municipality, South Africa: A cross-sectional study. African journal of reproductive health. 2018;22(1):113-9.

29. Ezegwui H, Nwogu-lkojo E, lkeako L, Nweze S. Trend in the use of Intra-uterine Contraceptive Device (IUCD, TCU 380A), in Enugu, Nigeria. Niger J Med. 2013;22(3):193-7.

30. Weldemariam KT, Gezae KE, Abebe HT. Reasons and multilevel factors associated with unscheduled contraceptive use discontinuation in Ethiopia: evidence from Ethiopian demographic and health survey 2016. BMC public health. 2019;19(1):1-15.

31. Samari G. Women's empowerment and short-and long-acting contraceptive method use in Egypt. Culture, Health \& Sexuality. 2018;20(4):458-73.

32. Kc S, Barakat B, Goujon A, Skirbekk V, Sanderson W, Lutz W. Projection of populations by the level of educational attainment, age, and sex for 120 countries for 2005-2050. Demographic research. 2010;22:383-472.

33. Melesse MB, Geremew AB, Abebe SM. High prevalence of cesarean birth among mothers delivered at health facilities in Bahir Dar city, Amhara region, Ethiopia. A comparative study. PloS one. 2020;15(4):e0231631.

34. Ayenew AA. Determinants of long-acting reversible contraceptive Utilization in Bahir Dar city, Ethiopia-results from the institutional-based cross-sectional study. 2019.

35. Staveteig S, Mallick L, Winter R. Uptake and discontinuation of long-acting reversible contraceptives (LARCs) in low-income countries: ICF International; 2015.

\section{Tables}

Due to technical limitations, table 6 is only available as a download in the Supplemental Files section.

\section{Figures}




\section{Conceptual Framework}

\begin{tabular}{|c|c|}
\hline$\frac{\text { Sociodemographic }}{\underline{\text { Factors }}}$ & $\frac{\text { Obstetric related }}{\text { factors }}$ \\
\hline $\begin{array}{l}\text { Age, Religion } \\
\text { Ethnicity, Education } \\
\text { Occupation, Marital } \\
\text { status, Husband's } \\
\text { Education, Husband's } \\
\text { occupation }\end{array}$ & $\begin{array}{l}\text { Parity, Abortion } \\
\text { No of children, Plan } \\
\text { /desire for pregnancy }\end{array}$ \\
\hline $\begin{array}{l}\text { Other factors } \\
\text { \&misconceptions } \\
\text { Reduced sexual activity// } \\
\text { Libido, Husband objection } \\
\text { Fear of migrate to other } \\
\text { body parts, Fear of cancer } \\
\text { Fear of infertility, } \\
\text { Neighbors' influence/Peer } \\
\text { pressure }\end{array}$ & $\begin{array}{l}\text { Contraceptive and Health } \\
\text { facility-related factors } \\
\text { Counseling, Follow up, Side effects, } \\
\text { Past contraceptive, Type of LARC } \\
\text { used, Place of LARC provided, } \\
\text { Who choses LARC, No husband } \\
\text { Expulsion of IUCD, Loss of implant in } \\
\text { the arm, Become pregnant }\end{array}$ \\
\hline
\end{tabular}

Figure 1

Conceptual framework for factors associated with LARCs adapted from pieces of literature, BahirDar, 2021(1) 
Two months' enrollment in Heath facilities of Bahir Dar city was obtained from the family planning registration book for sample selection (April 01/2020 -May 30/2020).

Bahir Dar city Health facilities those provide FP services including LARCs (11)

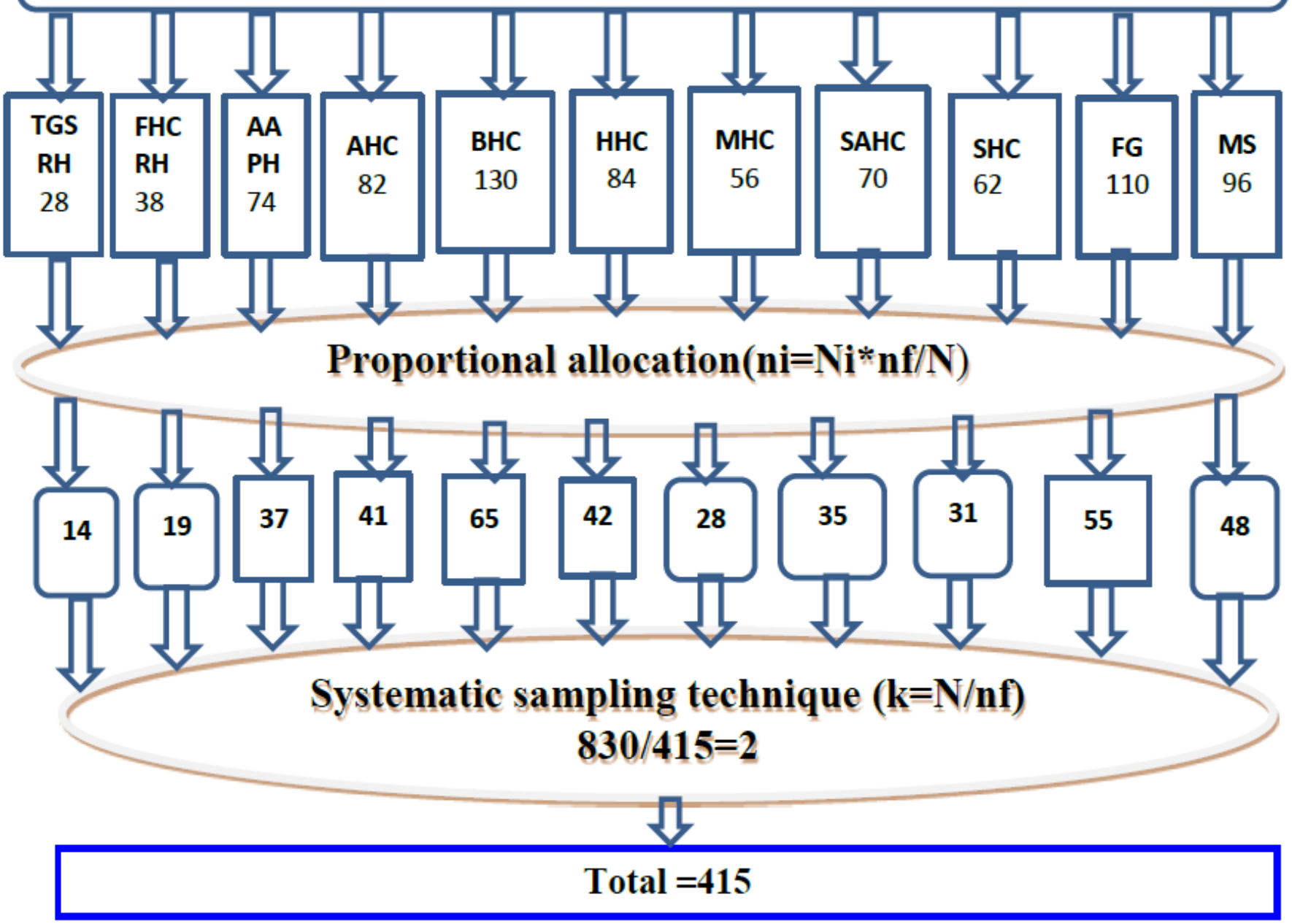

Figure 2

Schematic presentation of sampling the procedure for discontinuation of reversible long-acting contraceptives and associated factors, Bahir Dar city, 2021 


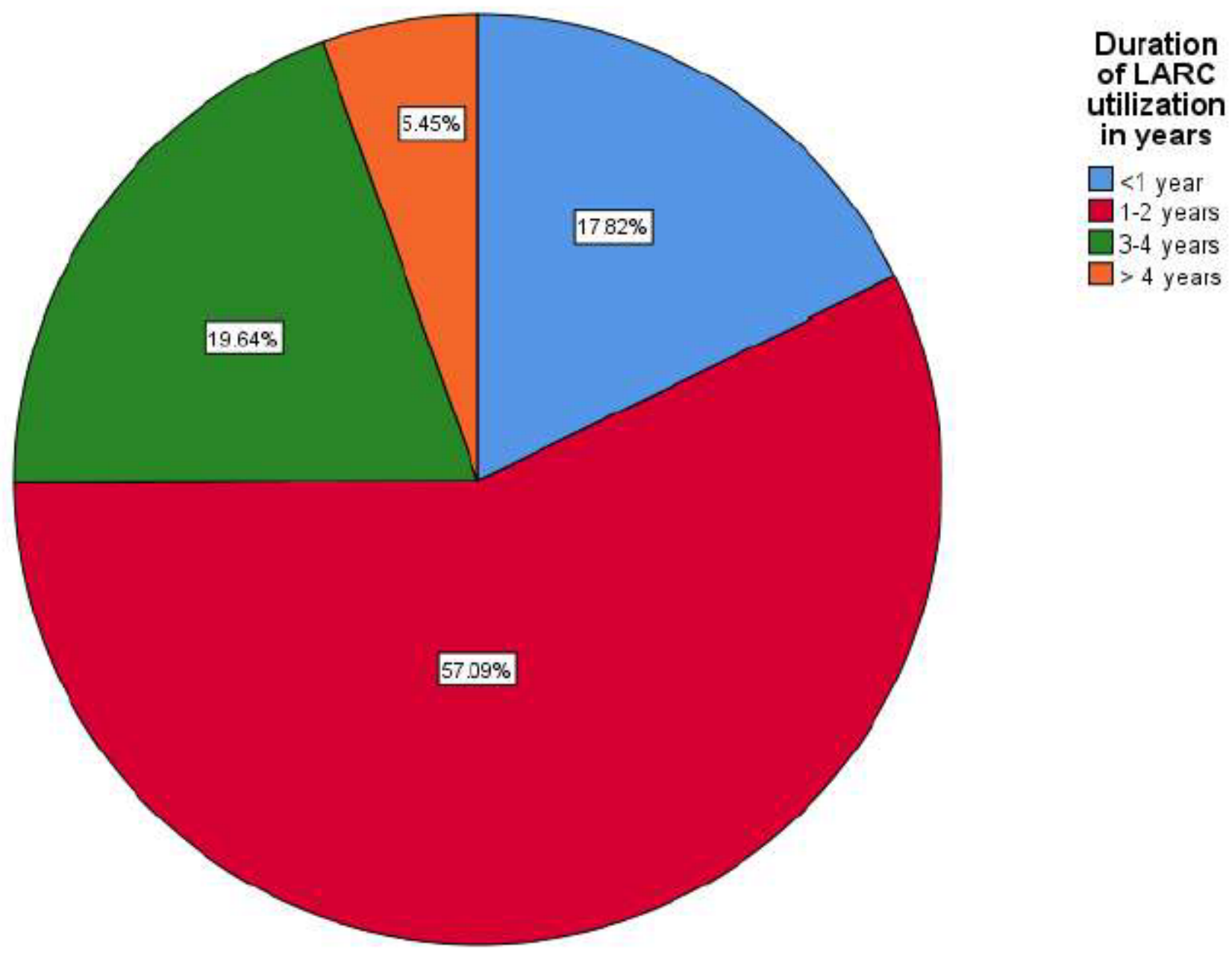

Figure 3

Duration of LARC utilization in years among women who discontinued LARCs in Bahr Dar city health facilities, Northwest Ethiopia, 2021( $n=275$ )

\section{Supplementary Files}

This is a list of supplementary files associated with this preprint. Click to download.

- Table6.docx 